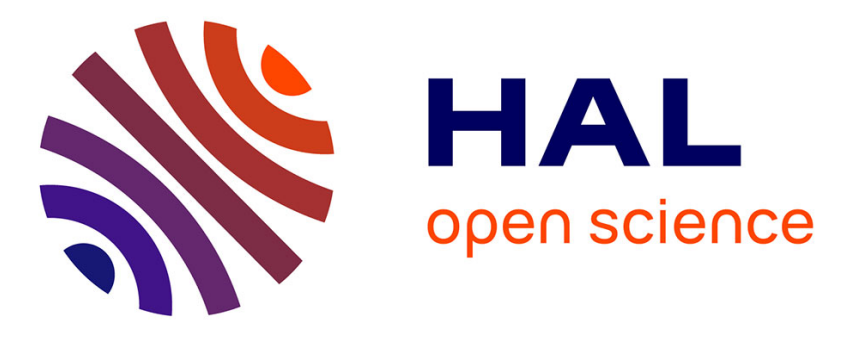

\title{
Modelling light-dark regime influence on the carbon-nitrogen metabolism in a unicellular diazotrophic cyanobacterium
}

\author{
Ghjuvan Micaelu Grimaud, Anthony Dron, Sophie Rabouille, Antoine \\ Sciandra, Olivier Bernard
}

\section{To cite this version:}

Ghjuvan Micaelu Grimaud, Anthony Dron, Sophie Rabouille, Antoine Sciandra, Olivier Bernard. Modelling light-dark regime influence on the carbon-nitrogen metabolism in a unicellular diazotrophic cyanobacterium. CAB, Dec 2013, Mumbai, India. 10.3182/20131216-3-IN-2044.00025 . hal00854479

HAL Id: hal-00854479

https://hal.inria.fr/hal-00854479

Submitted on 27 Aug 2013

HAL is a multi-disciplinary open access archive for the deposit and dissemination of scientific research documents, whether they are published or not. The documents may come from teaching and research institutions in France or abroad, or from public or private research centers.
L'archive ouverte pluridisciplinaire HAL, est destinée au dépôt et à la diffusion de documents scientifiques de niveau recherche, publiés ou non, émanant des établissements d'enseignement et de recherche français ou étrangers, des laboratoires publics ou privés. 


\title{
Modelling light-dark regime influence on the carbon-nitrogen metabolism in a unicellular diazotrophic cyanobacterium
}

\author{
Ghjuvan Micaelu Grimaud ${ }^{*, \star}$ Anthony Dron ${ }^{* *, * * *}$ \\ Sophie Rabouille ${ }^{* *, * * *}$ Antoine Sciandra ${ }^{* * * * *}$ \\ Olivier Bernard *,* \\ * BIOCORE-INRIA, BP93, 06902 Sophia-Antipolis Cedex, France \\ ** UPMC Univ Paris 06, UMR 7093, LOV, Observatoire \\ oceanologique, F-06234, Villefranche/mer, France \\ *** CNRS, UMR 7093, LOV, Observatoire oceanologique, F-06234, \\ Villefranche/mer, France
}

\begin{abstract}
We propose a dynamical model depicting nitrogen $\left(\mathrm{N}_{2}\right)$ fixation (diazotrophy) in a unicellular cyanobacterium, Crocosphaera watsonii, grown under light limitation and obligate diazotrophy. In this model, intracellular carbon and nitrogen are both divided into a functional pool and a storage pool. An internal pool that explicitly describes the nitrogenase enzyme is also added. The model is successfully validated with continuous culture experiments of $C$. watsonii under three light regimes, indicating that proposed mechanisms accurately reproduce the growth dynamics of this organism under various light environments. Then, a series of model simulations is run for a range of light regimes with different photoperiods and daily light doses. Results reveal how nitrogen and carbon are coupled, through the diel cycle, with nitrogenase dynamics, whose activity is constrained by the light regime. We finally identify optimal productivity conditions.
\end{abstract}

Keywords: dynamic modelling, cyanobacteria, light regime, optimum

\section{INTRODUCTION}

Nitrogen-fixing cyanobacteria (diazotrophs) are important actors of biogeochemical cycles in (sub)-tropical oceans (Karl et al., 2002), where they can be responsible of 20 to $40 \%$ of the new primary production (Lee et al., 2002). The conspicuous, colonial cyanobacteria (Trichodesmium spp. (Carpenter and Romans, 1991)) were considered as the dominant marine diazotrophs, until the importance of unicellular $\mathrm{N}_{2}$-fixing cyanobacteria (UCYN, such as Crocosphaera watsonii Waterbury and Rippka (1989)) was pointed-out (Zehr et al., 2001). UCYN now prove widely abundant and active in the nitrogen cycle (Zehr et al., 2011).

These newly discovered nitrogen fixing cyanobacteria have a strong potential for biotechnological applications. They might provide nitrogen to microorganisms of interest, offering the economical and ecological alternative to the use of fertilizers. However, if UCYN are now more intensively studied, their physiology and the influence of physicochemical factor such as temperature or light remain poorly known. Understanding nitrogen fixation dynamics in cultivated UCYN is a pre-requisite to the development of such applications.

Carbon-nitrogen metabolism and growth in photoautotrophic organisms are constrained by environmental factors, such as light availability or photoperiod length.

\footnotetext{
* Corresponding authors

olivier.bernard\}@inria.fr

\{ghjuvan.grimaud,
}

Owing to the $\mathrm{O}_{2}$-sensitivity of the $\mathrm{N}_{2}$-fixing nitrogenase enzyme (Robson and Postgate, 1980), carbon and nitrogen acquisition in the UCYN $C$. watsonii are separated in time: $\mathrm{N}_{2}$ fixation is mainly restricted to the dark period when oxygenic photosynthesis does not occur (Mitsui et al., 1986). Such temporal segregation is allowed by carbon storage as carbohydrates. In order to study the coupling between photosynthesis and diazotrophy in $C$. watsonii, an experimental study was carried out with various photoperiod lengths (Dron et al., 2012a,b, 2013). On the basis of these experiments, we propose here a dynamical model of diazotrophy in the unicellular cyanobacterium $C$ watsonii. We tackle the effect of photoperiod length and daily light dose on the carbon-nitrogen coupling, and we identify conditions leading to an optimal combination for carbohydrates storage, nitrogen fixation and total biomass.

\section{MATERIAL AND METHODS}

\subsection{Experimental approach}

Experimental procedure is described in Dron et al. (2012a) and it is only briefly recalled here. Duplicate continuous cultures were maintained under three different photoperiod lengths $(12: 12,16: 8$ and 8:16 light:dark conditions. In all three light regimes, the irradiance followed a sinusoidal cycle with a maximum irradiance of $130 \mu \mathrm{mol}$ quanta $\mathrm{m}^{-2}$ $\mathrm{s}^{-1}$ at the mid-light period. 


\subsection{Model design}

The present mathematical model is designed to represent the coupling between carbon and nitrogen metabolism, in order to analyze how photoperiodism affects nitrogen assimilation. The only physico-chemical constraints are light limitation and obligate diazotrophy. We focus on the growth of $C$. watsonii in terms of total organic carbon $C_{t o t}$ (biomass), and all considered variables are bulk concentrations.

In line with Rabouille et al. (2006), Ross and Geider (2009) and Mairet et al. (2010), we consider that organic carbon can be split into functional, storage and enzymatic pools. While the functional pool $C_{f}$ represents all structural material, among which membranes, nucleic acids and all proteins (except the nitrogenase), the storage pool $C_{s t}$ includes both small metabolites derived from photosynthesis and carbohydrate reserves. Last, the enzymatic pool $C_{n i t}$ represents active nitrogenase enzyme, expressed by its carbon content. In the same way, we consider that cellular nitrogen discriminates between a functional compartment and a storage compartment. The functional compartment $N_{f}$ includes the same molecules as $C_{f}$. We assumed constant stoichiometry for the functional compartment. $N_{f}$ is deduced from $C_{f}$ using the conversion parameter $\alpha_{3}$ :

$$
N_{f}=\alpha_{3} C_{f}
$$

The storage compartment $N_{s t}$ includes the first products of $\mathrm{N}_{2}$ fixation, mainly glutamine (Carpenter and Capone, 1992), and nitrogen reserve components such as cyanophycin (Li et al., 2001). The total organic nitrogen is denoted $N_{t o t}$. We consider that there is only one inorganic nitrogen source available for growth, $\mathrm{N}_{2}$, so that diazotrophy is obligate.

Metabolic reaction network is represented in Fig. 1 and can be encapsulated in a set of macroscopic reactions representing mass transfers (Bastin and Dochain, 1990). In the following we detail each considered metabolic reaction.

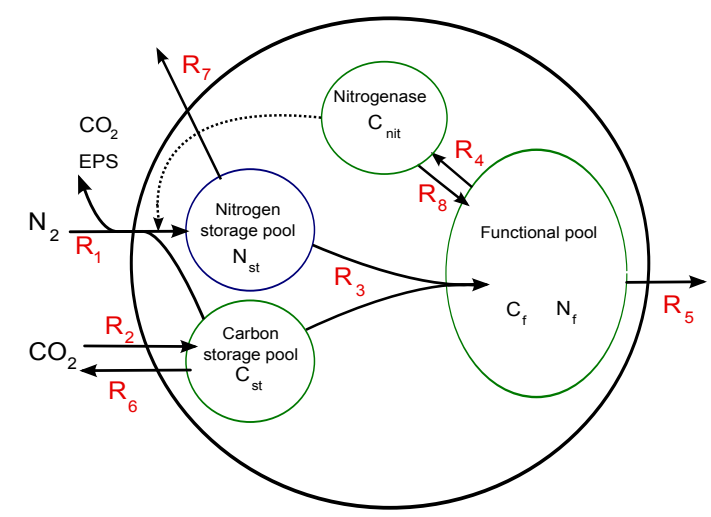

Fig. 1. Conceptual representation of carbon and nitrogen metabolism in C. watsonii. Black arrows represent mass fluxes between compartments, dashed arrows represent dependencies links. The different reactions are numbered $\left(R_{j}\right)$. Note that the functional compartment can either be expressed as nitrogen $\left(N_{f}\right)$ or carbon $\left(C_{f}\right)$.

Photosynthesis and reserves build up. During photosynthesis, $\mathrm{CO}_{2}$ is fixed and transformed into elemen- tary metabolites through the Calvin cycle. Then, these elemental organic carbon compounds are built into carbohydrates. Both processes feed the compartment $C_{s t}$, which thus mainly contains carbohydrates:

$$
R_{2}: \mathrm{CO}_{2} \stackrel{\rho_{2}\left(\mathrm{I}(\mathrm{t}), \mathrm{C}_{\mathrm{f}}\right)}{\longrightarrow} \mathrm{C}_{\mathrm{st}}
$$

This reaction $R_{2}$ is dependent upon the functional carbon $C_{f}$ which contains all the enzymatic apparatus. The carbon fixation rate $\rho_{2}(I)$, expressed in $\mu$ mol-C $/ \mathrm{L} / \mathrm{h}$, follows a Michaelis-Menten kinetics at low light intensity and deals with photoinhibition at high light intensity. This latter phenomenon, which is a slow and reversible reduction of the photosynthetic efficiency at high irradiance (Long et al., 1994), can be described by an haldane type function when the irradiance changes sufficiently slowly (Han, 2001):

$$
\rho_{2}(I)=r_{2} \frac{I(t)}{I(t)+K_{I}+\frac{I^{2}}{K_{i I}}} C_{f}
$$

where $I(t)$ is the irradiance value at time $t, K_{I}$ is the half-saturation constant of carbon fixation with respect to light, $r_{2}$ is the maximum carbon fixation rate, and $K_{i I}$ is an inhibition coefficient.

Biosynthesis of functional molecules. Functional carbon and nitrogen are metabolized from carbon and nitrogen reserves, through, e.g., protein synthesis. We assumed that biosynthesis of functional carbon $C_{f}$ and functional nitrogen $N_{f}$ are simultaneous, with a constant $C_{f} / N_{f}$ stoichiometry:

$$
R_{3}: C_{s t}+\alpha_{3} N_{s t} \stackrel{\rho_{3}\left(N_{s t}, C_{s t}\right)}{\longrightarrow} C_{f}+\alpha_{3} N_{f}+\mathrm{CO}_{2}
$$

where the specific rate $\frac{\rho_{3}\left(N_{s t}, C_{s t}\right)}{C_{s t}}$ of reaction $R_{3}$ is assumed to be proportional to the available nitrogen $N_{s t}$ :

$$
\rho_{3}\left(N_{s t}, C_{s t}\right)=\beta_{3} N_{s t} C_{s t}
$$

with $\beta_{3}$ the synthesis rate of functional carbon biosynthesized from $C_{s t}$. Functional nitrogen is synthesized from stored nitrogen $N_{s t}$, concomitantly to the synthesis of functional carbon from $C_{s t}$.

Diazotrophy and nitrogenase synthesis. Nitrogen fixation is an energy consuming process. Required energy is provided by the catabolism of stored carbohydrates (Mitsui et al., 1986).The macroscopic nitrogen fixation process results from three processes (respiration, nitrogen excretion and $\mathrm{N}_{2}$ uptake). We thus considered that this process relies on the catabolism of $C_{s t}$, which supports the direct costs of $\mathrm{N}_{2}$ fixation:

$$
\begin{aligned}
& R_{1}: N_{2}+\alpha_{1} C_{s t} \stackrel{\rho_{1}\left(C_{s t}, C_{n i t}\right)}{\longrightarrow} 2 N_{s t}+x \mathrm{CO}_{2} \\
&+y C_{\text {excreted }}
\end{aligned}
$$

where $C_{\text {excreted }}$ is the fraction of carbon excreted in the form of extracellular polymeric substances (EPS) (Dron et al., 2012b). Also, $x+y=\alpha_{1}$. All nitrogen fixed is stored into $N_{s t}$. This reaction depends on the compartment $C_{n i t}$, assuming that nitrogenase activity is linearly dependent on nitrogenase quantity. Energy requirements for diazotrophy are fuelled by $C_{s t}$. Therefore, the rate at which $\mathrm{N}_{2}$ is fixed is taken as a Michaelis-Menten function of $C_{s t}$ :

$$
\rho_{1}\left(C_{s t}, C_{n i t}\right)=\gamma_{1} \frac{C_{s t}}{C_{s t}+K} C_{n i t}
$$


where $\gamma_{1}$ is the maximal rate of $N_{2}$ fixation and $K$ is the half-saturation constant of nitrogen fixation.

Because the enzymatic apparatus is included inside $C_{f}$, we assumed that the nitrogenase is synthesized from $C_{f}$ :

$$
\begin{aligned}
& R_{4}: C_{f} \stackrel{\rho_{4}\left(\phi(t), C_{f}\right)}{\longrightarrow} C_{n i t} \\
& \rho_{4}\left(\phi(t), C_{f}\right)=\phi(t) r_{4} C_{f}
\end{aligned}
$$

where $r_{4}$ is the maximum, specific rate of nitrogenase synthesis. As detailed hereafter, cell-cycle plays a key role in nitrogenase synthesis.

Nitrogenase synthesis and cell-cycle clock. Nitrogenase is synthesized de novo each day (Chow and Tabita, $1994)$ and the rate $\rho_{4}\left(\phi(t), C_{f}\right)$ of nitrogenase synthesis is assumed to depend on the average position of the cell into its division cycle, represented by the function $\phi(t)$. This function takes into account the circadian clock, adjusted to the maximal irradiance time $T_{I_{\max }}$. The use of such time function is motivated by the fact that a highly conserved time pattern was reported in cultures of $C$. watsonii grown under a rather wide range of light regimes Dron et al. (2013). This cyanobacterium enters cell division close to the mid-light period; the cell division period lasts for 4.5 to 5.5 hours. Nitrogenase activity only appears 4.5 to 6 hours after the onset of cell division. The trigger for nitrogen fixation to start is not the onset of the dark but the completion of cell mitosis. In the end, a constant, 10 to 11 hours delay has been reported between the onset of cell division and the beginning of nitrogenase activity, which could correspond to an incompressible time before cells get ready for nitrogenase activity (genes expression and regulation; Dron et al. (2013)). The mid-light phase is thus a reliable mark from which to count down the time length before nitrogenase becomes active. Also, nitrogen fixation never lasts for more than 12 hours under all light regimes (Dron et al., 2013). Therefore, the function $\phi(t)$ defines a time window in the light cycle when nitrogenase can be synthesized and is active. The time window $\phi(t)$ finally begins 11 hours after the mid light phase and lasts for about 6 hours:

$$
\left\{\begin{array}{l}
\phi(t)=1 \\
\text { for } \mathrm{t} \bmod 24 \in\left(\mathrm{T}_{\mathrm{I}_{\max }}+11 ; \mathrm{T}_{\mathrm{I}_{\max }}+17\right) \\
\phi(t)=0 \text { else }
\end{array}\right.
$$

where $T_{I_{\max }}$ is the time at which $I(t)$ is maximum.

Due to a daily degradation of the nitrogenase complex, the enzyme concentration decreases as synthesis also stops after a few hours (Chow and Tabita, 1994). The nitrogenase decrease follows a constant, per capita degradation rate, and is proportional to the enzyme concentration :

$$
\begin{gathered}
R_{8}: C_{n i t} \stackrel{\rho_{8}\left(C_{n i t}\right)}{\longrightarrow} C_{f} \\
\rho_{8}\left(C_{n i t}\right)=r_{8} C_{n i t}
\end{gathered}
$$

where $r_{8}$ is the rate of nitrogenase degradation. We assumed that the products of nitrogenase degradation are not excreted.

Loss processes Grosskopf and LaRoche (2012a) reported that $C$. watsonii operates a 'respiratory protection' mechanism to limit nitrogenase inhibition by reducing the intracellular $p \mathrm{O}_{2}$. We thus considered that respiration of carbon reserves $C_{s t}$ further increases when diazotrophy and pho- tosynthesis co-occur, as an indirect cost of diazotrophy. We assumed that respiration is then linearly dependent upon photosynthesis, to compensate $\mathrm{O}_{2}$ production, and also proportional to the rate of $\mathrm{N}_{2}$ fixation:

$$
\begin{gathered}
R_{6}: C_{s t} \stackrel{\rho_{6}\left(C_{f}, I(t), C_{n i t}, C_{s t}\right)}{\longrightarrow} \mathrm{CO}_{2} \\
\rho_{6}\left(C_{s t}\right)=\left[\lambda_{6} \rho_{1}\left(C_{s t}, C_{n i t}\right) \rho_{2}\left(C_{f}, I(t)\right)+r_{6}\right] C_{s t}
\end{gathered}
$$

where $\lambda_{6}$ is the parameter that takes into account the cost of the co-occurrence of diazotrophy and photosynthesis. We also added a constant respiration term $r_{6}$, which accounts for the metabolic maintenance costs.

To embody the excretion of dissolved organic carbon, the functional compartment $C_{f}$ is degraded at a constant rate $\beta_{5}$ :

$$
\begin{gathered}
R_{5}: C_{f}+\alpha_{3} N_{f} \stackrel{\rho_{5}\left(N_{f}, C_{f}\right)}{\longrightarrow} x_{o r g} \\
\rho_{5}\left(N_{f}\right)=\beta_{5} N_{f} C_{f}
\end{gathered}
$$

where $x_{\text {org }}$ represents organic molecules excreted as amino acids or proteins. Because $N_{f}$ and $C_{f}$ are the same molecules, they are degraded simultaneously with a rate of degradation proportional to the $N / C$ stoichiometry of the functional compartment.

Diazotrophic cyanobacteria discharge a significant proportion of the recently fixed $\mathrm{N}_{2}$ (Mulholland et al., 2004). We therefore represented nitrogen excretion as a constant proportion of the activity of nitrogen fixation, lost from the stored nitrogen $N_{s t}$ (reaction $R_{7}$ ), which implies that the higher the fixation rate, the more nitrogen is excreted:

$$
\begin{gathered}
R_{7}: N_{\text {stock }} \stackrel{\rho_{7}\left(N_{\text {stock }}\right)}{\longrightarrow} \mathrm{DON} \\
\rho_{7}\left(N_{\text {stock }}\right)=r_{7} N_{\text {stock }} \\
\left\{\begin{array}{l}
\dot{C}_{s t}=r_{2} \frac{I(t)}{I(t)+K_{I}} C_{f}-\left[\beta_{3} N_{s t}+\alpha_{1} \frac{\gamma_{1}}{C_{s t}+K} C_{n i t}\right. \\
\left.+\lambda_{6} \rho_{1}\left(C_{s t}, C_{n i t}\right) \rho_{2}\left(C_{f}, I(t)\right)+r_{6}+D\right] C_{s t} \\
\dot{C}_{f}=\beta_{3} C_{s t} N_{s t}-\left(\beta_{5} N_{f}+r_{4} \phi(t)+D\right) C_{f} \\
\dot{N}_{s t}=\gamma_{1} \frac{C_{s t}}{C_{s t}+K} C_{n i t}-\left(\alpha_{3} \beta_{3} C_{s t}+r_{7}+D\right) N_{s t} \\
\dot{C}_{n i t}=r_{4} \phi(t) C_{f}-\left(r_{8}+D\right) C_{n i t}
\end{array}\right.
\end{gathered}
$$

Model equations are described in the system (14); parameters and state variables are listed in Tab. 1.

The model was run using Matlab ${ }^{\circledR} 7.9 .0$ with the solver ode23 applying Runge-Kutta method.

\subsection{Model calibration and sensitivity}

All model parameters were estimated but $K_{I}$ and $K_{i I}$ which were chosen in agreement with the work of Goebel et al. (2008), who considered that photoinhibition is visible 
from $600 \mu \mathrm{E} \mathrm{m}^{2} \mathrm{~s}^{-1}$ in C. watsonii. The parameters estimation was performed in the maximum-likelihood sense. The maximum-likelihood estimator is given as:

$$
\begin{gathered}
(\hat{\theta}, \hat{\Sigma})=\arg \min _{\theta, \Sigma}\left[\frac{n_{t}}{2} \ln \operatorname{det} \Sigma+\frac{1}{2} \sum_{i=1}^{n_{t}}\left[y\left(t_{i}\right)-\right.\right. \\
\left.\left.y_{m}\left(t_{i}, \theta\right)\right]^{T}\left[y\left(t_{i}\right)-y_{m}\left(t_{i}, \theta\right)\right]\right]
\end{gathered}
$$

where $y\left(t_{i}\right)$ is the vector of data collected at time $t_{i}$, $y_{m}\left(t_{i}\right)$ is the vector of data collected at time $t_{i}$ minus the measurement errors, $\theta$ is the parameter vector, $\hat{\theta}$ is the estimated parameter vector, $\Sigma$ is the covariance matrix of the measurement errors $\epsilon_{i}, n_{t}$ is the number of observation times and $\hat{\Sigma}$ is the maximum-likelihood estimate of the covariance matrix. We assumed that $\Sigma$ is unknown and diagonal, so that the maximum-likelihood estimator for $\theta$, which minimizes the cost function is:

$$
J(\theta)=\sum_{k=1}^{n_{y}} \frac{n_{t}}{2} \ln \left[\sum_{\mathrm{i}=1}^{\mathrm{n}_{\mathrm{t}}}\left[\mathrm{y}_{\mathrm{k}}\left(\mathrm{t}_{\mathrm{i}}\right)-\mathrm{y}_{\mathrm{m}_{\mathrm{k}}}\left(\mathrm{t}_{\mathrm{i}}, \hat{\theta}\right)\right]^{2}\right]
$$

where the maximum-likelihood estimate of the covariance matrix $\hat{\Sigma}$ is:

$$
\begin{gathered}
\hat{\Sigma}=\operatorname{diag}\left(\hat{\sigma}_{1}^{2}, \ldots, \hat{\sigma}_{\mathrm{n}_{\mathrm{y}}}^{2}\right) \\
\text { with } \hat{\sigma}_{\mathrm{k}}^{2}=\frac{1}{\mathrm{n}_{\mathrm{t}}} \sum_{\mathrm{i}=1}^{\mathrm{n}_{\mathrm{t}}}\left[\mathrm{y}_{\mathrm{k}}\left(\mathrm{t}_{\mathrm{i}}\right)-\mathrm{y}_{\mathrm{m}_{\mathrm{k}}}\left(\mathrm{t}_{\mathrm{i}}, \hat{\theta}\right)\right]^{2}
\end{gathered}
$$

The matlab toolbox IDEAS (Muñoz Tamayo et al., 2009) was used to estimate the model parameters using a maximum-likelihood criterion. The experiment under intermediate photoperiod (12:12 LD regime) was used for the calibration. We compared sets of data POC, PON, carbohydrates and nitrogenase activity to the quantity $C_{\text {tot }}, N_{\text {tot }}, C_{s t}$ and to the nitrogen inflow, respectively. The model was then validated with two other experiments (8:16 and 16:8 LD regimes), using the same parameters set. The closeness between the model and the experimental data was quantified using the coefficient of determination $\mathrm{R}^{2}$.

A sensitivity analysis was also performed using IDEAS (Muñoz Tamayo et al., 2009) to determine the key parameters and the robustness of the model. The sensitivity analysis is given as a matrix representation of the norm of the normalized sensitivities $(A)$ where the element $\left(a_{k, j}\right)$ of the matrix is:

$$
a_{k, j}=\sum_{i=1}^{n}\left|\frac{\hat{\theta}_{j}}{y_{m_{k}}\left(t_{i}, \hat{\theta}\right)}\left[\frac{\partial y_{m_{k}}}{\partial \theta_{j}}\right]\right|
$$

with $\hat{\theta}_{j}$ the $j^{\text {th }}$ value of $\hat{\theta}, y_{m_{k}}$ the $k^{\text {th }}$ value of $y_{m}$.

Results show that a small number of parameters strongly impacts the model dynamics under both light regimes. More precisely, some parameters influence a variable in particular. Highest sensitivity is observed in regard to $r_{2}$, which controls the inorganic carbon fixation during photosynthesis. It is worth noting that the nitrogen com-

\begin{tabular}{|c|c|}
\hline State variables & Unit \\
\hline$C_{f}$, functional carbon pool & $\mu m o l[C] L^{-1}$ \\
\hline$C_{s t}$, carbohydrates pool & $\mu \operatorname{mol}[C] L^{-1}$ \\
\hline$C_{n i t}$, nitrogenase pool & $\mu \operatorname{mol}[C] L^{-1}$ \\
\hline$N_{s t}$, nitrogen storage pool & $\mu \operatorname{mol}[N] L^{-1}$ \\
\hline Ordinary variables & \\
\hline$N_{f}$, functional nitrogen pool & $\mu \mathrm{mol}[N] L^{-1}$ \\
\hline$C_{\text {tot }}$, total carbon of C.watsonii & $\mu \operatorname{mol}[C] L^{-1}$ \\
\hline $\begin{array}{l}N_{\text {tot }} \text {, total nitrogen of C.watsonii } \\
\text { Forcing variables }\end{array}$ & $\mu \operatorname{mol}[N] L^{-1}$ \\
\hline$I(t)$, irradiance & $\mu E m^{-2} s^{-1}$ \\
\hline$T$, photoperiod & $h^{-1}$ \\
\hline Parameters & \\
\hline$r_{2}, \mathrm{CO}_{2}$ fixation rate & $0.205 h^{-1}$ \\
\hline$r_{4}$, nitrogenase synthesis rate & $0.006 h^{-1}$ \\
\hline$r_{6}$, respiration of reserves from $C_{s t}$ & $0.042 h^{-1}$ \\
\hline$r_{7}$, degradation rate of $N_{s t}$ & $0.02 h^{-1}$ \\
\hline$r_{8}$, nitrogenase degradation rate & $0.83 h^{-1}$ \\
\hline$\alpha_{1}$, catabolism of $C_{s t}$ for $\mathrm{N}_{2}$ fixation & $0.25 \mu \mathrm{mol}[C] \mu \mathrm{mol}[N]^{-1}$ \\
\hline$\alpha_{3}, N_{f}$ synthesis & $0.155 \mu \mathrm{mol}[N] \mu \mathrm{mol}[C]^{-1}$ \\
\hline$\beta_{3}$, functional carbon synthesis rate & $0.0006 \mu \mathrm{mol}[N]^{-1} L h^{-1}$ \\
\hline$\beta_{5}$, degradation rate of $C_{f}$ & $0.00005 \mu \mathrm{mol}[N]^{-1} L h^{-1}$ \\
\hline$\gamma_{1}, \mathrm{~N}_{2}$ fixation rate & $16 \mu \mathrm{mol}[N] \mu \mathrm{mol}[C]^{-1} h^{-1}$ \\
\hline$\lambda_{6}$, respiratory protection & $0.022 \mu \mathrm{mol}[C]^{-1} \mu \mathrm{mol}[N]^{-1} L^{2} h$ \\
\hline$K$, half-saturation constant for $R_{1}$ & $200 \mu \mathrm{mol}[C] L^{-1}$ \\
\hline$D$, dilution rate & $0.0083 h^{-1}$ or $0.0062 h^{-1}$ \\
\hline$\phi(t)$, cell-cycle parameter & adimensional \\
\hline$K_{I}$, half-saturation constant & $55.5 \mu E m^{-2} s^{-1}$ \\
\hline$K_{i I}$, light-inhibition coefficient & $1500\left(\mu E m^{-2} s^{-1}\right)^{2}$ \\
\hline
\end{tabular}
partment $N_{t o t}$ is mostly influenced by the variation of this parameter. Other important parameters are $r_{4}$ and $r_{8}$, involved in the synthesis and degradation of the nitrogenase enzyme. The parameter $\gamma_{1}$, controlling the respiration of
Table 1. Model variables and parameters.

$C_{s t}$ for diazotrophy, shows a strong effect on the carbon dynamics, in particular on the carbon stored.

The parameter $\lambda_{6}$, representing the 'respiratory protection', has a stronger effect when photoperiod is longer, since photosynthesis and diazotrophy co-occur in this condition.

\section{RESULTS AND DISCUSSION}

\subsection{Model simulation}

The present model is designed to reproduce the observed, diel fluctuations in the carbon and nitrogen metabolism of C. watsonii when light limitation and obligate diazotrophy occur.

All model simulations were performed with the unique set of parameters obtained after calibration on the 12:12 LD experiment. Different runs were performed using successively the three light regimes as forcing conditions and results were then compared to experimental data obtained under the same three light regimes. The initial conditions for $C_{t o t}, N_{t o t}$ and $C_{s t}$ are fixed to the corresponding experimental data, considering that total carbohydrates in cells can be used as first approximation of the initial $C_{s t}$. Conversely, variables $N_{s t}$ and $C_{n i t}$, for which there is no direct experimental match, can be initiated with a wider degree of freedom. Simulation were initiated at the beginning of a light period, assuming empty nitrogenase pool $C_{n i t}$ and nitrogen reserve $N_{s t}$. The initial value of $C_{f}$ is deduced from $C_{s t}$.

The model reaches a periodic behavior in each simulation. Comparisons were made between total biomasses expressed as carbon $\left(C_{t o t}\right.$ and POC) and nitrogen $\left(N_{t o t}\right.$ and PON), and between the measured cellular carbo- 
hydrates and the variable $C_{s t}$. Results, shown in Fig. 3 demonstrate that the model predicts the dynamics of cellular carbon, nitrogen and carbohydrates pools with fair accuracy. $C_{f}$ and $N_{f}$ pools are not compared to data but they participate to the correct $C_{t o t}$ and $N_{t o t}$ dynamics. The $N_{t o t} / C_{t o t}$ ratio follows that observed experimentally. Thus, the accumulation or decrease of the carbon reserves $C_{s t}$ results from an imbalance between photosynthesis and carbohydrates consumption (through respiration and biosynthesis of functional components) and model results comply with the observation that carbon is stored during the photoperiod and largely consumed during the dark period to fuel diazotrophy.

The nitrogen inflow $\rho_{1}\left(C_{s t}, C_{n i t}\right)$ compares well to the experimental nitrogenase activity (nitrogen fixed/L/h). Results (Fig. 2) show that the model, by taking into account the timing bracketed by the cell-cycle for nitrogen fixation, correctly reproduces the different patterns of nitrogenase activity observed under all light regimes.
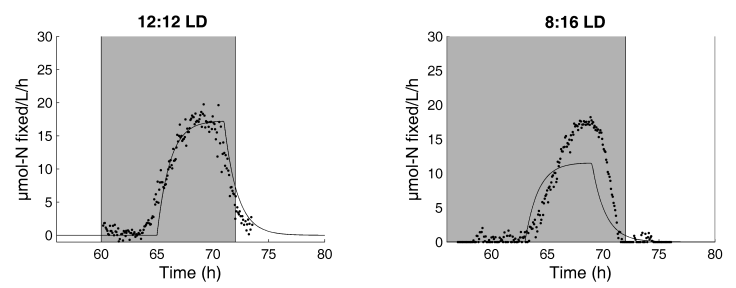

Fig. 2. Simulated (continuous line) and measured (dots) nitrogenase activity under the 12:12 LD and 8:16 LD light regimes, during 24 hours. White and grey backgrounds represent the light and dark periods, respectively.
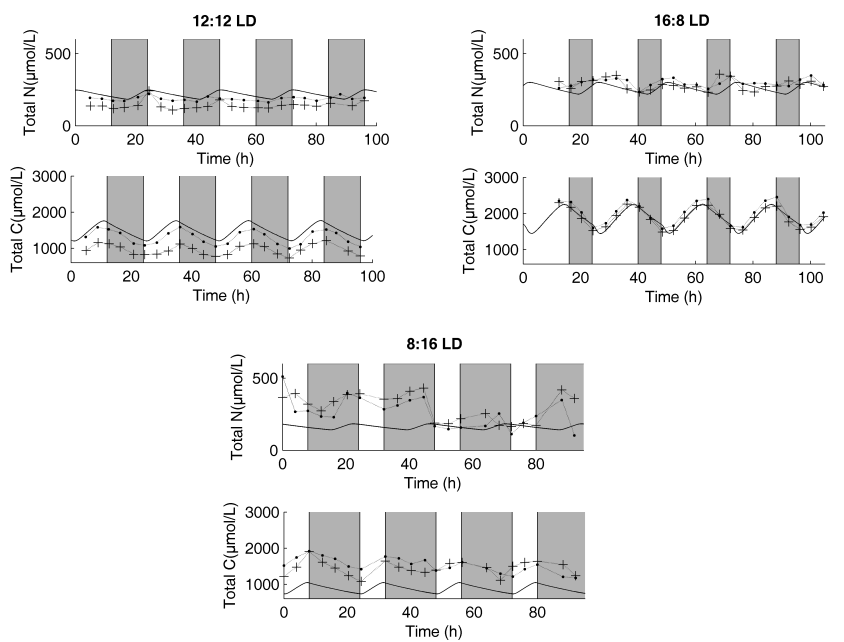

Fig. 3. Model simulation of $C_{t o t}, N_{t o t}, C_{s t}$ and $C_{t o t} / N_{t o t}$ (continuous lines) compared to the experimental data of POC, PON, carbohydrates and PON/POC (dashed lines), respectively, under the three light regimes. The experimental duplicates are represented by closed circles and crosses. White and grey backgrounds represent the light and dark periods, respectively.

\subsection{Influence of the photoperiod and light dose}

In order to understand the role of photoperiodism on the dynamics of carbon and nitrogen metabolism in $C$. watsonii, the model was run for a range of photoperiods. First, we considered various photoperiods associated with the same daily light dose $\left(3.743 \mathrm{E} / \mathrm{m}^{2} / \mathrm{d}\right)$ corresponding to the 16:8 LD experiment. For each photoperiod, we used conditions obtained in the permanent regime after an initial transient as initial conditions for each run.

We quantified the carbon and nitrogen budgets for each photoperiod. We determined the total nitrogen fixed in $N_{s t}$ (gross) during 24 hours $\left(N_{\text {fixed }}\right)$ :

$$
N_{\text {fixed }}=\int_{0}^{24} \rho_{1}\left(C_{s t}(t), C_{n i t}(t)\right) \mathrm{d} t
$$

Similary, we compared the total carbon stored into $C_{s t}$ (gross) during one day, $\mathrm{CH}_{\text {fixed }}$, the total carbon integrated over one day, $C_{t_{\text {tot }}}$ and the total nitrogen integrated over one day, $N_{\text {tot }_{d}}$.

Results, identify an optimal photoperiod of $14.5 \mathrm{~h}$ for $N_{\text {fixed }}, 14 \mathrm{~h}$ for $C_{t o t}$ and $N_{\text {tot }}$, and $16 \mathrm{~h}$ for $C H_{\text {fixed }}$. Interestingly, optimal photoperiod for carbon and nitrogen acquisitions are very close. A balance between the quantity of carbohydrates stored and respired, depending upon the light-dark timing, explains this result. The amount of carbohydrates stored during the day depends on the photosynthesic activity $\rho_{2}\left(I(t), C_{f}\right)$.

To understand the additional effect of light dose, we combined simulations at different photoperiod length and daily light doses. We ran simulations from a daily light dose of $2 \mathrm{E} \mathrm{m}^{2} \mathrm{~d}^{-1}$ to $60 \mathrm{E} \mathrm{m}^{2} \mathrm{~d}^{-1}$.

The variables of interest are $C_{\text {tot }}, N_{\text {tot }}, N_{\text {fixed }}, C H_{\text {fixed }}$, estimated at steady-state (Fig.4). Simulations were performed with a dilution rate that equals the growth rate $\left(D=0.0083 \mathrm{~h}^{-1}\right)$. Results show that there is an optimal photoperiod/light intensity combination for all these variables: for example, a photoperiod comprised between $12 \mathrm{~h}$ and $15 \mathrm{~h}$ light and a daily light dose comprised between 7 $\mathrm{E} / \mathrm{m}^{2} / \mathrm{d}$ and $20 \mathrm{E} / \mathrm{m}^{2} / \mathrm{d}$ for $N_{\text {fixed }}$ (which is representative of the other variables).

The optimal duration of light decreases with increasing irradiances. This phenomenon is due to the respiratory protection, which increases when photosynthesis increases, and by photoinhibition that limits growth at high light intensity.

\section{CONCLUSION}

We presented a dynamical growth model of a unicellular, diazotrophic cyanobacterium under light limitation and obligate diazotrophy. The model is successfully calibrated and validated against experimental data of C.watsonii exposed to different light-dark cycles. Simulations highlight how the carbon and nitrogen metabolism are tightly connected through the dynamics of carbohydrate reserves.

Simulations carried out with a range of light regimes and various photoperiods reveal the optimal photoperiod/intensity combination for the accumulation of carbohydrates and nitrogen.

\section{ACKNOWLEDGEMENTS}

This work was supported by the ANR Facteur 4 project and the LEFE-CYBER project CROCOCYCLE, the Con- 

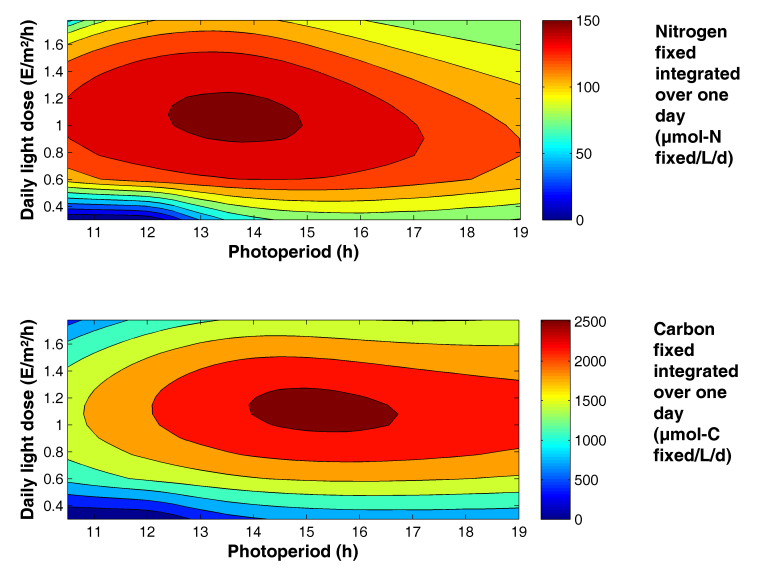

Fig. 4. Model simulation of the carbon fixed integrated over one day $\mathrm{CH}_{\text {fixed }}$ (top) and nitrogen fixed integrated over one day $N_{\text {fixed }}$ (bottom) as a function of the daily light dose and photoperiod.

seil Régional des Alpes Maritimes and the Conseil Général PACA. We are grateful to Rafael Muñoz-Tamayo for his helpful suggestions concerning model calibration.

\section{REFERENCES}

Bastin, G. and Dochain, D. (1990). On-line estimation and adaptive control of bioreactors. In Amsterdam. Elsevier.

Carpenter, E. and Capone, D. (1992). Nitrogen fixation in Trichodesmium spp. in: Carpenter e.j., capone d.g. \& rueter j. (eds) marine pelagic cyanobacteria: Trichodesmium and other diazotrophs. Kluwer Academic Publishers, The Netherlands; Appl Environ Microbiol, 211-217.

Carpenter, E. and Romans, K. (1991). Major role of the cyanobacterium Trichodesmium in nutrient cycling in the north atlantic ocean. Science, 254, 1356-1358.

Chow, T. and Tabita, F. (1994). Reciprocal light-dark transcriptional control of nif and rbc expression and light-dependent posttranslational control of nitrogenase activity in synechococcus sp strain rf-1. Journal Of Bacteriology, 176, 6281-6285.

Dron, A., Rabouille, S., Claquin, P., Chang, P., Raimbault, V., Talec, A., and Sciandra, A. (2012b). Lightdark (12:12) quantification of carbohydrate fluxes in Crocosphaera watsonii. Aquat Micro Ecol, DOI: 10.3354/ame01600.

Dron, A., Rabouille, S., Claquin, P., Le Roy, B., Talec, A., and Sciandra, A. (2012a). Light-dark (12:12) cycle of carbon and nitrogen metabolism in Crocosphaera watsonii wh8501: relation to the cell cycle. Environ Microbiol, 14, 967-981.

Dron, A., Rabouille, S., Claquin, P., and Sciandra, A. (2013). Photoperiod length paces the temporal orchestration of cell cycle and carbon-nitrogen metabolism in Crocosphaera watsonii. Environ Microbiol, doi: 10.1111/1462-2920.12163.

Goebel, N., Edwards, C., Carter, B., Achilles, K., and Zehr, J. (2008). Growth and carbon content of three different-sized diazotrophic cyanobacteria observed in the subtropical north pacific. J Phycol, 44, 1212-1220.

Grosskopf, T. and LaRoche, J. (2012a). Direct and indirect costs of dinitrogen fixation in Crocosphaera watsonii wh8501 and possible implications for the nitrogen cycle. Frontier in Microbiology, 3, 1-10.

Han, B.P. (2001). Photosynthesis-irradiance response at physiological level: A mechanistic model. J. Theor. Biol., 213, 121-127.

Karl, D., Michaels, A., Bergman, B., Capone, D., Carpenter, E., Letelier, R., Lipschultz, F., Paerl, H., Sigman, D., and Stal, L. (2002). Dinitrogen fixation in the world's oceans. Biogeochemistry, 57, 47-98.

Lee, K., Karl, D., Wanninkhof, R., and Zhang, J. (2002). Global estimates of net carbon production in the nitratedepleted tropical and subtropical oceans. Geophys Res Lett, 29, 257-268.

Li, H., Sherman, D., Bao, S., and Sherman, L. (2001). Pattern of cyanophycin accumulation in nitrogen-fixing and non-nitrogen-fixing cyanobacteria. Arch Microbiol, 176, 9-18.

Long, S.P., Humphries, S., and Falkowski, P.G. (1994). Photoinhibition of photosynthesis in nature. Annual Review of Plant Biology, 45, 633-662.

Mairet, F., Bernard, O., Masci, P., Lacour, T., and Sciandra, A. (2010). Modelling neutral lipid production by the microalga Isochrysis aff. galbana under nitrogen limitation. Bioresource Technology, 102, 142-149.

Mitsui, A., Kumazawa, S., Takahashi, A., Ikemoto, H., Cao, S., and Arai, T. (1986). Strategy by which nitrogen-fixing unicellular cyanobacteria grow photoautotrophically. Nature, 323, 720-722.

Muñoz Tamayo, R., Laroche, B., Leclerc, M., and Walter, E. (2009). Ideas: a parameter identification toolbox with symbolic analysis of uncertainty and its application to biological modelling. 15th Symposium on System Identification.

Mulholland, M., Bronk, D., and Capone, D. (2004). Dinitrogen fixation and release of ammonium and dissolved organic nitrogen by trichodesmium ims101. Aquat Microb Ecol, 37, 85-94.

Rabouille, S., Staal, M., Stal, L., and Soetaert, K. (2006). Modeling the dynamic regulation of nitrogen fixation in the cyanobacterium Trichodesmium sp. Appl Environ Microbiol, 72, 3217-3227.

Robson, R. and Postgate, J. (1980). Oxygen and hydrogen in biological nitrogen-fixation. Annu Rev Microbiol, 34, 183-207.

Ross, O. and Geider, R. (2009). New cell-based model of photosynthesis and photo-acclimation: accumulation and mobilisation of energy reserves in phytoplankton. Mar Ecol Progr Ser, 383, 53-71.

Waterbury, J. and Rippka, R. (1989). Cyanobacteria. subsection i. order chroococcales. In Bergey's Manual of Systematic Bacteriology, Krieg, N.R., and Holt, J.B. (eds). Baltimore, MD, USA: Williams and Wilkins, 3, 1728-1746.

Zehr, J., Tripp, H., Hilton, J., Moisander, P., and Foster, R. (2011). Ecological aspects of nitrogen-fixing cyanobacteria illuminated by genomics and metagenomics. Journal of Phycology, 47, S1-S1.

Zehr, J., Waterbury, J., Turner, P., Montoya, J., Omoregie, E., Steward, G., and al. (2001). Unicellular cyanobacteria fix $\mathrm{n}_{2}$ in the subtropical north pacific ocean. Nature, 412, 635-638. 